\title{
Touro Scholar
}

NYMC Faculty Publications

Faculty

3-1-2017

\section{Effect of Systemic Antioxidant Allopurinol Therapy on Skin Flap Survival}

\author{
M Ardakani \\ Kaveh Alizadeh \\ New York Medical College
}

A Moghadam

Follow this and additional works at: https://touroscholar.touro.edu/nymc_fac_pubs

Part of the Dermatology Commons, and the Pharmacology Commons

\section{Recommended Citation}

Ardakani, M., Alizadeh, K., \& Moghadam, A. (2017). Effect of Systemic Antioxidant Allopurinol Therapy on Skin Flap Survival. Advances in Plastic \& Reconstructive Surgery, 1 (2). Retrieved from https://touroscholar.touro.edu/nymc_fac_pubs/277

This Article is brought to you for free and open access by the Faculty at Touro Scholar. It has been accepted for inclusion in NYMC Faculty Publications by an authorized administrator of Touro Scholar. For more information, please contact touro.scholar@touro.edu. 


\title{
Effect of Systemic Antioxidant Allopurinol Therapy on Skin Flap Survival
}

\author{
Mehdi Rasti Ardakani', kaveh Alizadeh ${ }^{2 *}$, Ali Shayesteh Moghadam ${ }^{3}$ \\ ${ }^{1}$ Department of Plastic Surgery, School of Medicine, Isfahan University of Medical Sciences, Isfahan, Iran. \\ ${ }^{2}$ Chief of Plastic and Reconstructive Surgery, Westchester Medical Center, Associate Professor Surgery, New York Medical College. \\ ${ }^{3}$ Department of Plastic Surgery, Medical Education Research Center, Isfahan University of Medical Sciences, Isfahan, Iran.
}

\begin{abstract}
Background: This study was undertaken to evaluate whether steady state concentrations of allopurinol can improve ischemia in canine skin flaps.

Methods: Twenty dogs underwent one skin flap surgery with a 2-week interval. The first procedure was performed according to the standard protocols. The second phase was started by a 1-week pretreatment with allopurinol. Length of the necrotic zone was measured and recorded daily. At each phase, flaps were removed and sent for histopathological study after 1week observation.

Results: Mean length of the necrotic zone in allopurinol treated skin flaps has been significantly less than normal flaps over all 7 days of observation ( $\mathrm{p}$-value $<0.0001$ ). Histopathology study showed less inflammation and more normal tissue structure in the allopurinol treated skin flaps.

Conclusions: Findings obtained from our study demonstrate that systemic administration of allopurinol significantly improves skin flap survival and may have significant clinical implications.
\end{abstract}

Keywords: Allopurinol; Antioxidant; Skin necrosis; Reperfusion injury; Flaps; Tissue ischemia.

\section{Introduction}

Surgeons rely on skin flaps to reconstruct tissue defects resulting from trauma, ablative surgery or congenital malformation. Howeer, prolonged tissue ischemia in setting of trauma or prolonged procedures can lead to tissue necrosis and eventual demise of the skin flap $[1,2]$. Despite remarkable progress in plastic surgery over the previous two decades, partial flap necrosis has been reported in $7-20 \%$ of free flaps and $20-33 \%$ of pedicled flaps [3-9].

Ischemia-reperfusion (IR) injury is one of the most important causes of flap damage. IR injury likely results in a complex pathway involving neutrophil infiltration and production of superoxide free radicals which lead to irreversible tissue damage, need for reoperations, prolonged hospitalization and increased medical costs [10-14].

Xanthine oxidase (XO) plays an important role in the pathogenesis of IR injury. There is a significant up-regulation of $\mathrm{XO}$ system during ischemia of skin flaps $[15,16] . \mathrm{XO}$ is a major source of reactive oxygen species (ROS) which triggers release of several inflammatory mediators $[17,18]$. Allopurinol is an antioxidant drug,

\footnotetext{
${ }^{*}$ Address for Correspondence: Kaveh Alizadeh, Division of Plastic and reconstructive Surgery, Westchester Medical Center, Vahalla, New York, Tel: 212.348.0100; Fax: 516.439.5011; Email: drkaveha@gmail.com
}

Received: February 15, 2017; Date Accepted: March 10th, 2017; Date published: March 13, 2017. and inhibits XO. Hence, systemic administration of allopurinol reduces ROS formation and may improve survival rate of skin flaps $[19,20]$. However, effectiveness of allopurinol in improving skin flap survival is still controversial [21,22].

Given our understanding of IR and the ongoing controversies about the role of Allopurinol in the XO pathway, we set out to design a study to further elucidate the steady state concentration level of allopurinol required to improve skin flap survival in dogs.

\section{Materials and Methods}

This clinical trial was performed at veterinary research clinic of the Isfahan University Medical Centre. The study received IRB approval by the University ethics committee (391136) and adhered to the strict guidelines of the Helsinki Declaration.

Twenty male, healthy dogs aged between 3 to 4 years and mean weight of $5.4 \mathrm{~kg}$ (range $4-6 \mathrm{~kg}$ ) were included in the present study. All dogs had physical examination prior to the study. They had been completely vaccinated, and had received a complete course of anti parasite medication. All dogs were kept in separate cages during the study and were fed with normal diet.

The subjects were divided into two groups of ten (Group A and B). All dogs underwent one skin flap surgery by a single blinded surgeon (a total number of 20 skin flaps). Group A (control group) procedure was performed under the standard conditions with no additional medication. Group B procedure was performed similar to the first one, but all dogs were pre-treated with unlabeled use of oral 
allopurinol from one week before the surgery until 48 hours after skin flap surgery.

\section{Group A skin flap surgery}

After 12 hours of fasting, the surgical site (the back of the dogs) was shaved. Dogs were anaesthetized with ketamine $(75 \mathrm{mg} / \mathrm{kg}$ of body weight) and a cuffed endotracheal tube was inserted into the trachea. Then an island adipofascial cutaneous flap, $4 \times 24 \mathrm{~cm}$, was created in one side of the spinal column extending down to the fascia. Afterwards, the flap was sutured in place immediately using simple interrupted Nylon 1-0 sutures [Figure 1].

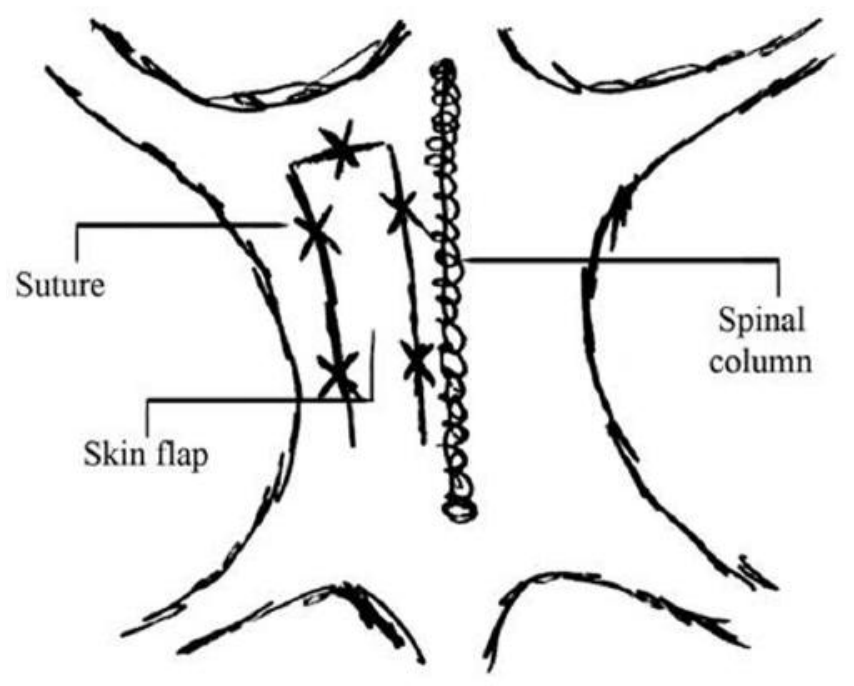

Figure 1: Schematic view of the surgical site and sutures' sites.

After the operation dogs were treated with appropriate dose of analgesics. In addition, a daily dose of $30 \mathrm{mg} / \mathrm{kg}$ Cefazolin was commenced intravenously 60 minutes prior and every day after surgery. All dogs were visited on a daily basis by a veterinarian and the surgeon to check the general condition and skin flap status. At the end of this one-week observation flaps were removed. After removal, flap site was closed with simple continuous suture of nylon-01.

\section{Group B skin flap surgery}

All ten dogs in second group received allopurinol (MD-Allopurinol ${ }^{\circledR} 100 \mathrm{mg}$, Mehr Darou, Tehran, Iran, daily dose of $50 \mathrm{mg} / \mathrm{kg}$ of body weight) through the nasogastric tube for 9 days ( 7 days prior to surgery, 2 days during the observation). Skin flap surgery was performed one week after commencing allopurinol. Otherwise, the second operation was completely similar to the first group one.

\section{Measurements}

All flaps were assessed daily regarding the size of the necrotic area. Surface of the necrotic area was measured by the surgeon in-vivo, using a single standard ruler with the accuracy of $1 / 10$ centimeter. All measurements were recorded in $\mathrm{cm}^{2}$. Length of the necrotic zone was defined as the longest distance between the necrotic edge and the survived area. Care was taken to ensure maintenance of a straight line during the measurement.

\section{Pathologic study of the skin flaps}

One week after each skin flap surgery, the skin flaps were removed, fixed in $10 \%$ formalin and sent for histopathological study. After hematoxylin and eosin $(\mathrm{H} \& \mathrm{E})$ and toluidine blue staining, all samples were investigated by a single pathologist who was unaware of the type of treatment. Samples were studied regarding the number of neutrophils, fibroblasts, mast cells and other inflammatory cells, using a light microscope.

\section{Statistical analysis}

Data was analyzed by SPSS 16.5 software. Independent- t test was used to compare mean length of necrotic zone between standard flaps and allopurinol treated flaps.

\section{Results}

Comparison of two types of skin flaps showed that mean total area of the necrotic zone in allopurinol treated skin flaps $\left(27.6 \mathrm{Cm}^{2}\right)$ have been significantly less than necrotic area in normal flaps $\left(78 \mathrm{Cm}^{2}\right)$ over all 7 days of observation [Figure 2]. Dogs in the control group presented an average of $81.25 \%$ of necrosis in the flap total area; those which received allopurinol presented an average of $28.75 \%$ of necrosis. Table 1 illustrates the changes in length of necrotic zone for both groups during observation time. Differences in area of necrotic zones increased proportionally with observation time $(\mathrm{P}<0.05)$. [Figure 3 and 4] represent skin flaps treated with allopurinol 3 and 7 days after skin flap surgery whereas [Figure 5 and 6] show control group without allopurinol treatment 3 and 7 days after skin flap surgery.

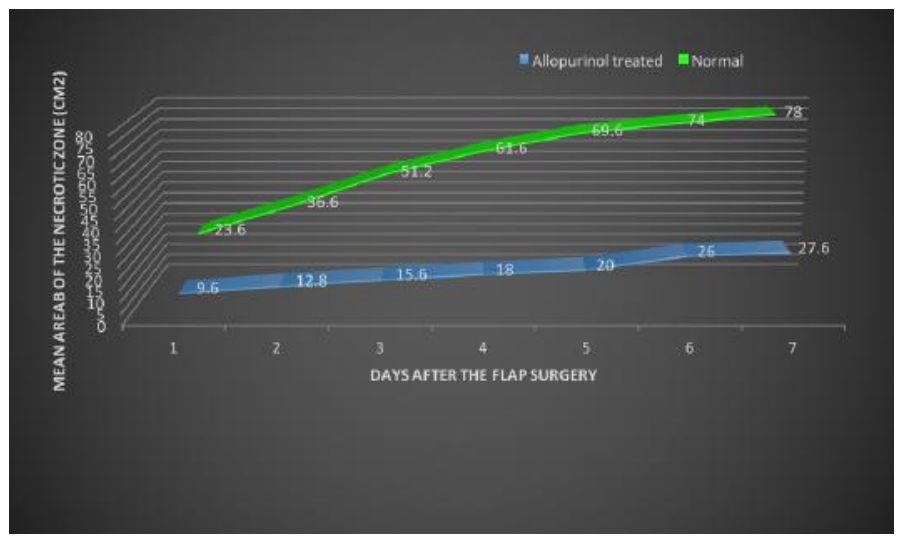

Figure 2: Illustration of changes in the mean area of necrotic zone in both groups. Data are presented as mean area of necrotic zone in $\mathrm{cm}^{2}$ in different days.

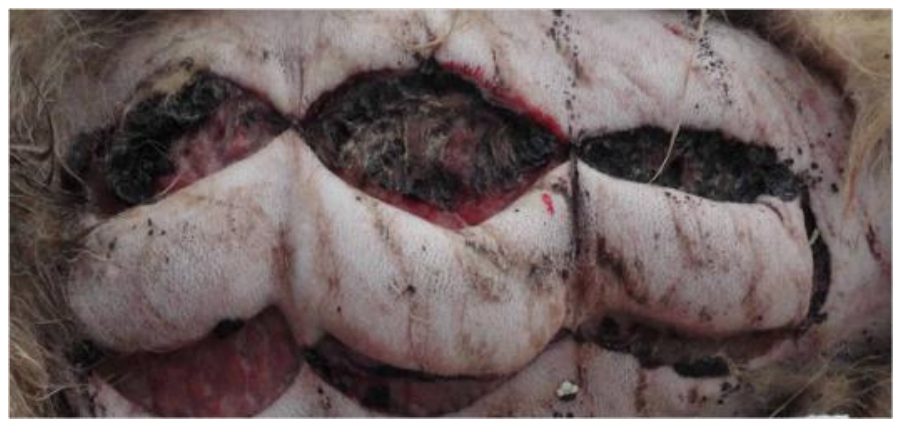

Figure 3: Postoperative view on allopurinol treated $\operatorname{dog} 3$ days after skin flap surgery. 


\begin{tabular}{|l|l|l|l|l|l|l|l|}
\hline & \multicolumn{7}{|c|}{ Mean length of the necrotic zone (cm) } \\
\cline { 2 - 8 } & Day 1 & Day 2 & Day 3 & Day 4 & Day 5 & Day 6 & Day 7 \\
\hline $\begin{array}{l}\text { Normal skin } \\
\text { flaps (n=10) }\end{array}$ & $5.9 \pm 0.6$ & $9.1 \pm 0.7$ & $12.7 \pm 0.5$ & $15.3 \pm 0.6$ & $17.4 \pm 0.7$ & $18.5 \pm 0.8$ & $19.4 \pm 0.7$ \\
\hline $\begin{array}{l}\text { Allopurinol } \\
\text { treated skin } \\
\text { flaps (n=10) }\end{array}$ & $2.4 \pm 0.3$ & $3.2 \pm 0.4$ & $3.9 \pm 0.5$ & $4.4 \pm 0.6$ & $5.0 \pm 0.6$ & $5.5 \pm 0.6$ & $5.8 \pm 0.6$ \\
\hline p-value & $<0.0001$ & $<0.0001$ & $<0.0001$ & $<0.0001$ & $<0.0001$ & $<0.0001$ & $<0.0001$ \\
\hline
\end{tabular}

Table 1: Comparison of mean length of necrotic zone between two types of flaps in different days. Data are presented as mean $( \pm S D)$ length of the necrotic zone, in $\mathrm{cm}$, during the observation time. $\mathrm{N}=$ number of cases; $\mathrm{SD}=$ standard deviation.

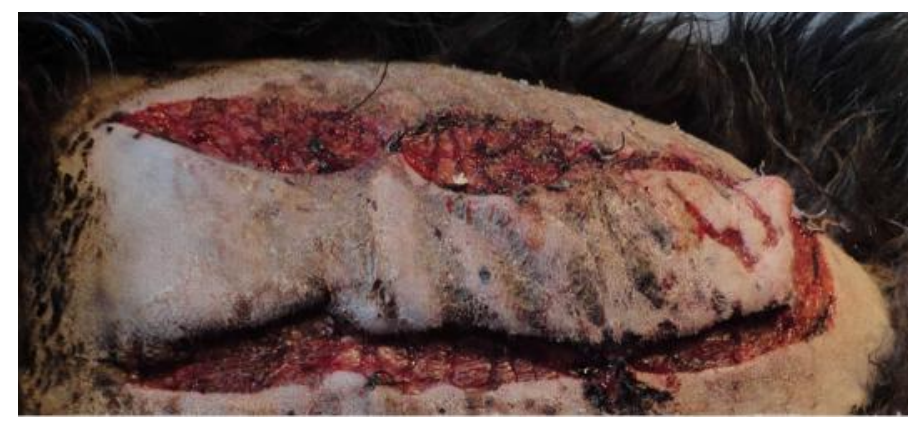

Figure 4: Vital flap mainly supplied by the basis allocated in allopurinol treated group 7 days after skin flap surgery.

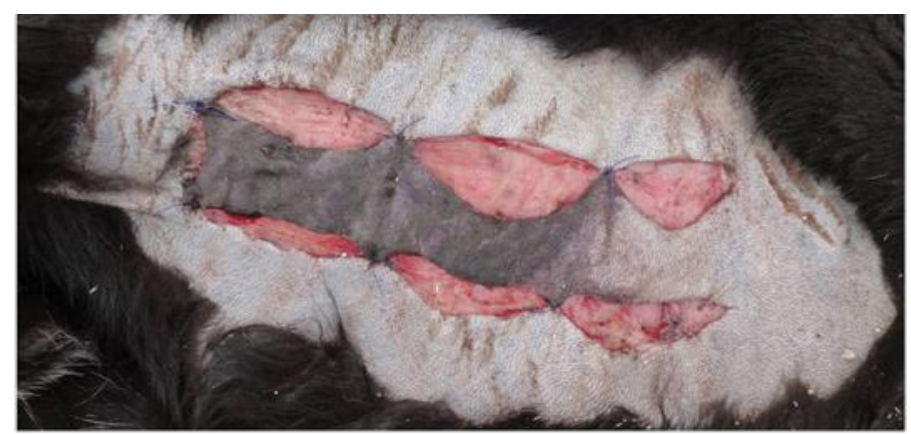

Figure 5: About two thirds of the base distant flap outlined to be necrotic without any allopurinol administration 3 days after skin flap surgery.

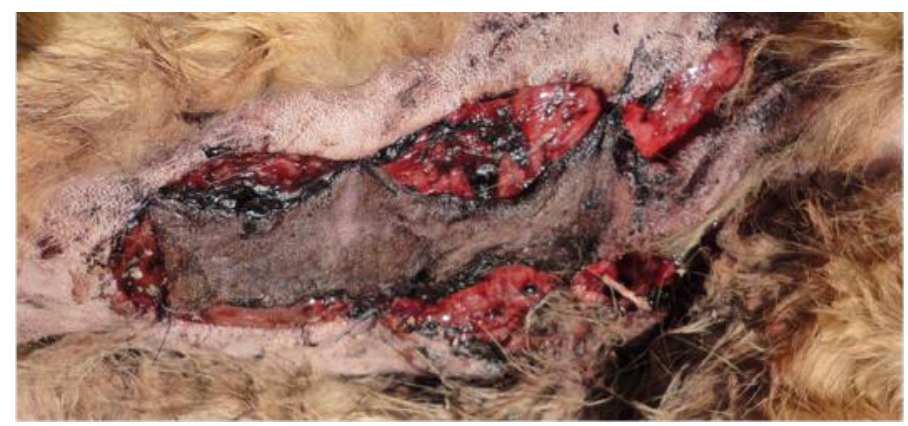

Figure 6: Insufficiently perfused flap of control group without any allopurinol treatment 7 days after skin flap surgery.

\section{Normal skin flaps findings of different zones}

1. Necrotic zone findings: Coagulative necrosis with large amounts of vessel thrombosis can be detected. A few neutrophils and fibrotic tissue in margins were seen [Figure 7a].

2. Transitional zone findings: Destruction of the epidermis in most of the regions. In superficial dermis there was infiltration of inflammatory cells - mostly neutrophils - between collagen bundles. Existing microabscess. More severe inflammation was found in the subcutis fat in form of non-septal panniculitis. Fat necrosis with intensive infiltration of inflammatory cells neutrophils, macrophage and lymphoplasma cells could be detected. Numerous dilated vessels with evidence of thrombosis in some of them were present [Figure 7b].

3. Intact zone findings: Moderate infiltration of inflammatory cells - macrophage and plasma cells - in the subcutaneous fat and deep dermis. There was focal fat necrosis. Furthermore, existing extravasation of red blood cells and vasodilatation [Figure 7c].

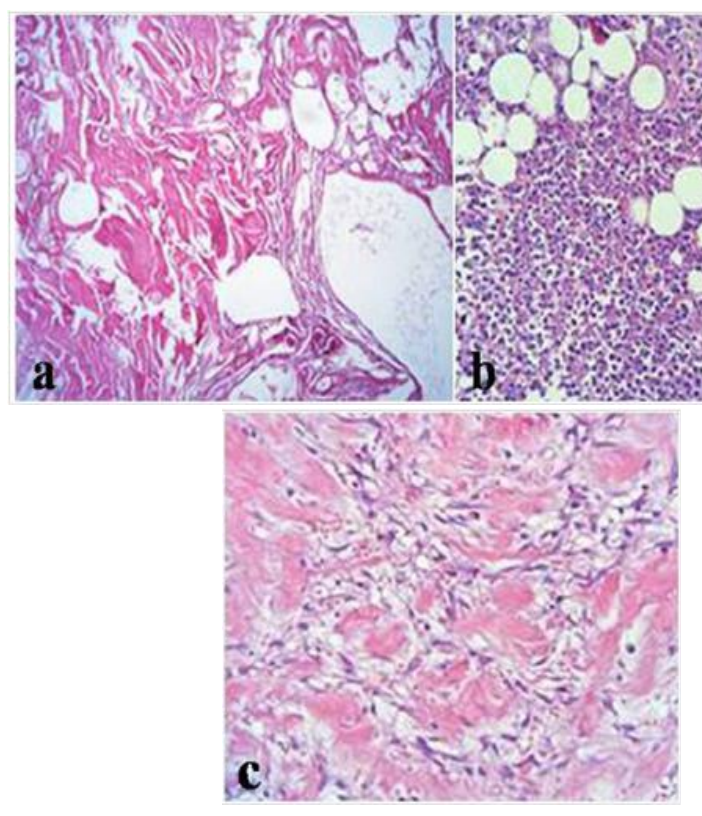

Figure 7: Histopathological findings of different zones of normal skin flap 7 days after skin flap surgery. A: necrotic zone, B: transitional zone, C: intact zone.

\section{Allopurinol treated skin flaps findings of different zones}

1. Necrotic zone findings: Shedding of the csuperficial epidermis. Intensive infiltration of inflammatory cells - neutrophils and macrophage - around the muscle bundles with focal microabscess and dilated vessels and thrombosis in some of them [Figure $8 \mathrm{a}, \mathrm{b}]$.

2. Transitional zone findings: Focal shedding of the epidermis accompanied by mild infiltration of neutrophils. Obvious red blood cell extravasation in superficial dermis. Severe panniculitis, fat necrosis, infiltration of neutrophils and dilated vessels with some thrombosis were seen in the deep dermis [Figure 8c].

3. Intact zone findings: Completely normal structure of the skin tissue [Figure 8d]. 


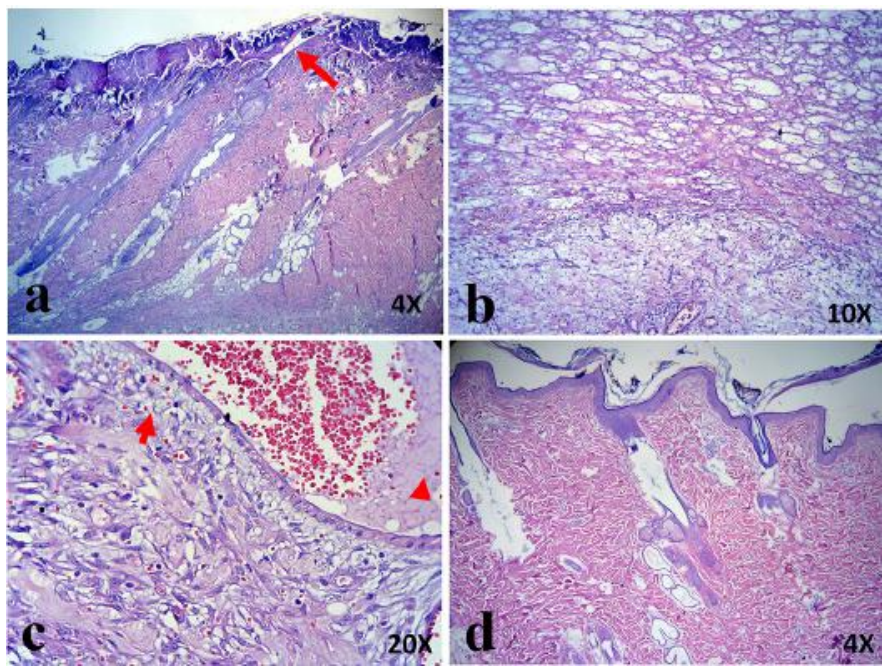

Figure 8: Histopathological findings of different zones of allopurinol treated skin flap 7 days after skin flap surgery. A,B: necrotic zone: shedding of the superficial epidermis (arrow) with infiltration of inflammatory cells. C: transitional zone: mild infiltration of neutrophils. Obvious red blood cell extravasation in superficial dermis (arrow), infiltration of neutrophils and dilated vessels with some thrombosis (arrow head), D: intact zone.

\section{Discussion}

Despite several treatment strategies which aim at reducing or preventing skin flap necrosis, improvement of the flap survival is still an important concern for surgeons. This study showed that pre- and post-treatment with allopurinol leads to significant reduction of the necrotic zone length, more normal histological structure and less inflammation of the skin tissue in dogs.

Allopurinol has been primarily used for treatment of hyperuricemia and gout [23], but based on its mechanism of action and its effects on endothelial function, it has been investigated as a novel medication for other medical problems [24-27]. Effects of allopurinol on survival of skin flaps are related to its mechanism of action and mechanisms which cause tissue damage [28].

ROS including oxygen ions, free radicals and peroxides are generated during ischemic phase and especially during reperfusion. The production of ROS over the reperfusion phase results in endothelial cell swelling, vasoconstriction and increased capillary permeability which impairs the microcirculation [20,29]. ROS are usually produced by two major mechanisms: The Nicotinamide Adenine Dinucleotide Phosphate (NADPH) oxidase system in neutrophils and the XO system in endothelium cells $[12,30,31]$. The $\mathrm{XO}$ system appears to be a major source of ROS $[12,32-34]$. The activity of this system significantly increases during the ischemia, and produces a large amount of ROS [20]. Therefore, it is not surprising to find that systemic administration of an XO inhibitor such as allopurinol improves skin flap survival.

A previous study performed by Tamir et al. confirms our findings by a different study design in rats. They investigated effects of allopurinol on survival of island skin grafts under prolonged period of ischemia and found it a useful method to improve skin flap survival [28]. They believe that pre-treatment with allopurinol enables skin grafts to tolerate longer periods of ischemia. This effect is contributed to the XO inhibitor properties of allopurinol. Another study by Im et al. also reported that allopurinol can improve skin flap survival in rats by inhibiting most of the increased activity of XO during IR, and consequently, by preventing tissue damage [35].

Picard-Ami et al. reported different levels of XO activity in rats, pigs and humans [36]. Therefore, in contrast to the above mentioned studies, they studied effects of allopurinol on skin flaps of pigs and found it ineffective [22]. This finding shows that although allopurinol can improve skin flap survival by reducing ROS levels, this effect is completely dependent on the level of $\mathrm{XO}$ activity in the target organ.

Even though critical flap monitoring is within 72 hours postoperatively [37], we did monitor the flaps over 1 week. Nevertheless, our study lacks an extended observation period and thus no statement can be made regarding long-term survival. The present experiment had some critical differences with aforementioned studies. Instead of rats which are most commonly used to investigate this subject, we used dogs. Accordingly, flaps dimensions can be dissected similar to possible human correlates and there is no size limitation like rats, also we chose to focus on dogs because we wanted to show the difference in a setting where the surface area of flaps raised would be similar to clinical scenarios in humans and the dog model was the closest animal that would be able to provide. More importantly, in contrast to the previous studies in which allopurinol was administrated a few hours before [22] or even after the procedure [28], in this study dogs were pre-treated with allopurinol for 1 week prior to the surgery which helped us to reach a steady plasma concentration of the drug.

In summary, findings obtained from our study demonstrated that systemic administration of allopurinol significantly improved skin flap survival and had a protective effect against flap necrosis in dogs. Clinical impressions were confirmed by histopathological examination.

Although results of this method regarding administration of allopurinol are promising, further studies such as comparison of XO activity of dogs with humans are required prior to apply it on humans. Furthermore, studies with even smaller dimensioned flaps and longer timelines should be planned. It would be of utmost interest to find clinical patients who are managed on Allopurinol for other medical conditions and see whether they respond better to flap surgery using in vivo vascular studies.

\section{Acknowledgments}

The authors declare no conflict of interests or source of funding.

\section{References}

1. Akan M, Cakir B, Misirlioglu A, Yildirim S, Taylan G, and Aköz T. Effects of clopidogrel and high dose aspirin on survival of skin flaps in rats. Scand J Plast Reconstr Surg Hand Surg. 2005; 39:7-10. [Crossref]

2. Forkvist L, Lofberg R, Raud $\mathbf{J}$ and Thorlacius H. Heparin protects against skin flap necrosis: relationship to neutrophil recruitment and anti-coagulant activity. Inflamm Res. 2004 ; 53:1-3. [Crossref]

3. Khouri RK, Cooley BC, Kunselman AR, Landis JR, Yeramian P, Ingram D, et al. A prospective study of microvascular free-flap surgery and outcome. Plast Reconstr Surg. 1998; 102:711-721. [Crossref]

4. Moran SL, Nava G, Behnam AB and Serletti JM. An outcome analysis comparing the thoracodorsal and internal mammary vessels as recipient sites for microvascular breast reconstruction: a prospective study of 100 patients. Plast Reconstr Surg. 2003; 111:1876-1882. [Crossref] 
5. Nahabedian MY, Momen B and Manson PN. Factors associated with anastomotic failure after microvascular reconstruction of the breast. Plast Reconstr Surg. 2004; 114:74-82. [Crossref]

6. Banic A, Boeckx W, Greulich M, Marchi A, Rigotti G and Tschopp H. Late results of breast reconstruction with free TRAM flaps: a prospective multicentric study. Plast Reconstr Surg. 1995; 95:1195-1204. [Crossref]

7. Moran SL and Serletti JM. Outcome comparison between free and pedicled TRAM flap breast reconstruction in the obese patient. Plast Reconstr Surg. 2001; 108:1954-1960. [Crossref]

8. Tanaka N, Yamaguchi A, Ogi K and Kohama G. Sternocleidomastoid myocutaneous flap for intraoral reconstruction after resection of oral squamous cell carcinoma. J Oral Maxillofac Surg. 2003; 61:1179-1183. [Crossref]

9. Wei FC, Celik N, Chen HC, Cheng MH and Huang WC. Combined anterolateral thigh flap and vascularized fibula osteoseptocutaneous flap in reconstruction of extensive composite mandibular defects. Plast Reconstr Surg. 2002; 109:45-52. [Crossref]

10. Cetin C, Kose AA, Aral E, Colak O, Erçel C, Karabağli Y, et al. Protective effect of fucoidin (a neutrophil rolling inhibitor) on ischemia reperfusion injury: experimental study in rat epigastric island flaps. Ann Plast Surg. 2001; 47:540-546. [Crossref]

11. Rand-Luby L, Pommier RF, Williams ST, Woltering EA, Small KA and Fletcher WS. Improved outcome of surgical flaps treated with topical dimethylsulfoxide. Ann Surg. 1996; 224:583-589. [Crossref]

12. Kerrigan CL and Stotland MA. Ischemia reperfusion injury: a review. Microsurgery. 1993; 14:165-175. [Crossref]

13. Gute DC, Ishida T, Yarimizu K and Korrhuis RJ. Inflammatory responses to ischemia and reperfusion in skeletal muscle. Mol Cell Biochem. 1998; 179:169-187. [Crossref]

14. Gideroglu K, Alagoz S, Uygur F, Evinc R, Celikoz B and Bugdayci G. Effects of nebivolol on skin flap survival: A randomized experimental study in rats. Curr Ther Res Clin Exp. 2008; 69:449-458. [Crossref]

15. Im MJ, Hoopes JE, Yoshimura Y, Manson PN and Bulkley GB. Xanthine:acceptor oxidoreductase activities in ischemic rat skin flaps. J Surg Res. 1989; 46:230-234. [Crossref]

16. Angel MF, Im MJ, Chung HK, Vander Kolk CA and Manson PN. Effects of combinced cold and hyperbaric oxygen storage on free flap survival. Microsurgery. 1994; 15:648-651. [Crossref]

17. Li C and Jackson RM. Reactive species mechanisms of cellular hypoxia-eoxygenation injury. Am J Physiol Cell Physiol. 2002; 282:227-241. [Crossref]

18. Ilhan H, Alatas O, Tokar B, çOlak O, Paşaoĝlu O and Koku N. Effects of the antiICAM-1 monoclonal antibody, allopurinol, and methylene blue on intestinal reperfussion injury. J Pediatr Surg. 2003; 38:1591-1595. [Crossref]

19. Milcheski DA, Nakamoto HA, Tuma P, Nóbrega L and Ferreira MC. Experimental Model of Degloving Injury in Rats: Effect of Allopurinol and Pentoxifylline in Improving Viability of Avulsed Flaps. Ann Plast Surg. 2013; 70:366-369. [Crossref]

20. van den Heuvel MG, Buurman WA, Bast A and van der Hulst RR. Ischaemia-reperfusion injury in flap surgery. J Plast Reconstr Aesthet Surg. 2009; 62:721-726. [Crossref]

21. Rees R, Smith D, Li TD, Cashmer B, Garner W, Punch J, et al. The role of xanthine oxidase and xanthine dehydrogenase in skin ischemia. J Surg Res. 1994; 56:162-167. [Crossref]

22. Picard-Ami LA Jr, MacKay A and Kerrigan CL. Effect of allopurinol on the survival of experimental pig flaps. Plast Reconstr Surg. 1992; 89:1098-1103. [Crossref]
23. Rundles RW. The development of allopurinol. Arch Intern Med. 1985; 145:1492-1503. [Crossref]

24. Butler R, Morris AD, Belch JJ, Hill A and Struthers AD. Allopurinol normalizes endothelial dysfunction in type 2 diabetics with mild hypertension. Hypertension. 2000; 35:746-751. [Crossref]

25. Doehner W, Schoene N, Rauchhaus M, Leyva-Leon F, Pavitt DV, Reaveley DA, et al. Effects of xanthine oxidase inhibition with allopurinol on endothelial function and peripheral blood flow in hyperuricemic patients with chronic heart failure: results from 2 placebo-controlled studies. Circulation. 2002; 105:2619-2624. [Crossref]

26. Farquharson CAJ, Butler R, Hill A, Belch JJ and Struthers AD. Allopurinol improves endothelial dysfunction in chronic heart failure. Circulation. 2002; 106:221-226. [Crossref]

27. Guthikonda S, Sinkey C, Barenz T and Haynes WG. Xanthine oxidase inhibition reverses endothelial dysfunction in heavy smokers. Circulation. 2003; 107:416-421. [Crossref]

28. Tamir G, Yaffe B, Pri-Chen S, Hauben DJ and Tsur H. The effect of allopurinol on experimental island skin flap survival under prolonged periods of arterial ischaemia. Br J Plast Surg. 1994; 47:155-157. [Crossref]

29. Manson PN, Narayan KK, Im MJ, Bulkley GB and Hoopes JE. Improved survival in free skin flap transfers in rats. Surgery. 1986; 99:211-215. [Crossref]

30. Siemionow $\mathrm{M}$ and Arslan E. Ischemia/reperfusion injury: a review in relation to free tissue transfers. Microsurgery. 2004; 24:468-475. [Crossref]

31. Harder Y, Amon M, Laschke MW, Schramm R, Rücker M, Wettstein R, et al. An old dream revitalised: preconditioning strategies to protect surgical flaps from critical ischaemia and ischaemia-reperfusion injury. J Plast Reconstr Aesthet Surg.2008; 61:503-511. [Crossref]

32. Ozmen S, Ayhan S, Demir Y, Siemionow M and Atabay K. Impact of gradual blood flow increase on ischaemia-reperfusion injury in the rat cremaster microcirculation model. J Plast Reconstr Aesthet Surg. 2008; 61:939-948. [Crossref]

33. Feng GM, Yang WG, Huan-Tang Chen S, Chu YM, Tsai LM, Chang TM,et al. Periodic alterations of jejunal mucosa morphology following free microvascular transfer for pharyngoesophageal reconstruction. J Plast Reconstr Aesthet Surg. 2006; 59:1312-1317. [Crossref]

34. Aydogan H, Gurlek A, Parlakpinar H, Ibrahim Askar, Aysun Bay-Karabulut, Nilay Aydogan, et al. Beneficial effects of caffeic acid phenethyl ester (CAPE) on the ischaemia-reperfusion injury in rat skin flaps. J Plast Reconstr Aesthet Surg. 2007; 60:563-568. [Crossref]

35. Im MJ, Shen WH, Pak CJ, Manson PN, Bulkley GB and Hoopes JE . Effect of allopurinol on the survival of hyperemic island skin flaps. Plast Reconstr Surg. 1984; 73:276-278. [Crossref]

36. Picard-Ami LA, Jr., MacKay A and Kerrigan CL. Pathophysiology of ischemic skin flaps: differences in xanthine oxidase levels among rats, pigs, and humans. Plast Reconstr Surg. 1991; 87:750-755. [Crossref]

37. Cornejo A, Ivatury S, Crane CN, Myers JG and Wang HT. Analysis of free flap complications and utilization of intensive care unit monitoring. J Reconstr Microsurg. 2013; 29:473-479. [Crossref] 